\section{Commentary: Culture trumps (transfusion) guidelines}

\author{
Christopher T. Ryan, MD, and Todd K. Rosengart, MD
}

Transfusion indications have been the subject of intense debate in cardiac surgery and the broader medical community, with multiple, high-profile international randomized trials exploring this subject. ${ }^{1-3}$ The focus of these studies has been the elucidation of an optimal hemoglobin concentration to use as a transfusion trigger, with recent trials demonstrating that a restrictive strategy (eg, hemoglobin $\leq 7.5-8.0 \mathrm{~g} / \mathrm{dL}$ ) to be noninferior to a liberal strategy (eg, hemoglobin $\geq 9.0$ $10.0 \mathrm{~g} / \mathrm{dL}){ }^{1-3}$ A second, growing body of literature is now affirming earlier suggestions that allogeneic transfusion of any kind is independently associated with diminished shortand long-term survival. ${ }^{4,5}$ Although lingering skepticism persists regarding the possibility of an associative rather than causal relationship between transfusion and mortality (ie, only ill patients get transfused), the growing number of randomized trials exploring this matter is increasingly putting this claim to rest. The actual pathophysiology underlying this relationship nevertheless remains uncertain, but may be related to immunogenic or other longer-term mechanisms. ${ }^{6}$ Given this mortality risk and shorter-term complications such as transfusion-related lung injury, transfusion-related sepsis, allergic reactions, costs, and resource consumption, the case seems to be well made that unnecessary transfusions are a bad thing. Why then are patients still receiving unnecessary transfusions?

Fitzgerald and colleagues ${ }^{7}$ report their findings using sophisticated statistical analyses to probe a dedicated, multi-institutional surgical and perfusion record database of 22,272 adult cardiac surgery patients seeking to isolate factors responsible for institutional differences in transfusion patterns. They note that interinstitutional

\footnotetext{
From the Michael E. DeBakey Department of Surgery, Baylor College of Medicine, Houston, Tex.

Disclosures: The authors reported no conflicts of interest.

The Journal policy requires editors and reviewers to disclose conflicts of interest and to decline handling or reviewing manuscripts for which they may have a conflict of interest. The editors and reviewers of this article have no conflicts of interest.

Received for publication April 26, 2020; revisions received April 26, 2020; accepted for publication April 27, 2020; available ahead of print May 11, 2020.

Address for reprints: Todd K. Rosengart, MD, Michael E. DeBakey Department of Surgery, 6501 Fannin St, Suite NC114, Houston, TX 77030 (E-mail: Todd. Rosengart@bcm.edu).

J Thorac Cardiovasc Surg 2022;163:1025-6

$0022-5223 / \$ 36.00$

Copyright (c) 2020 by The American Association for Thoracic Surgery

https://doi.org/10.1016/j.jtcvs.2020.04.129
}

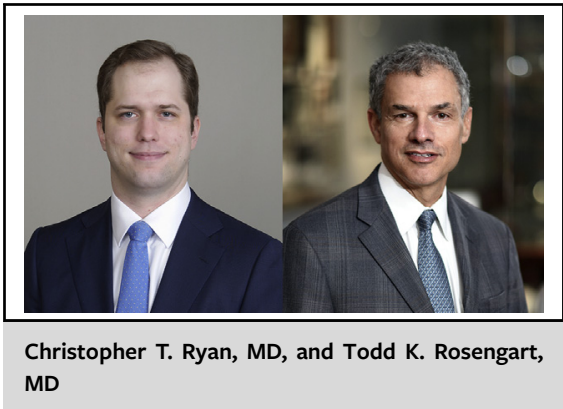

CENTRAL MESSAGE

Cultural elements may affect the establishment of patient care best practices such as transfusion rates.

differences in transfusion practice could not be traced or explained by differences in the implementation of transfusion guidelines or even patient risk factors. A substantial portion of the interinstitutional variance they found remained unexplained after adjusting for these and other similar variables. The authors instead conclude that the cause of this variability may instead be organizational culture.

The influence of culture on provider behavior is an important element in considering the current avalanche of guidelines facing the medical community. In the context of the findings presented by Fitzgerald and colleagues, ${ }^{7}$ it seems clear that efforts focused on achieving effective cultural integrity and management proficiency are as critical, if not more critical, than good data in changing practices to provide better care. Likewise, it cannot be taken for granted that familiarity with research findings or guidelines will lead to changes in practice. This is particularly true for management changes such as modifying transfusion practices, which require coordinated input from numerous providers, including collaboration between surgeons, perfusionists, anesthesiologists, and intensivists. ${ }^{8}$ In this case, implementation of a culture change could, for example, be accomplished within a blood conservation team that establishes a local consensus for transfusion strategy before transfusion decisions need to be made for a specific patient. This a priori consensus building enables providers to make better collective decisions while freeing cognitive resources to optimize the remainder of the operation. ${ }^{9,10}$ However, this type of visible intervention is only effective if it is integrated within a culture characterized by a foundational commitment to 
continuous self-assessment and care improvement at the department and hospital levels.

Peter Drucker famously said, "culture eats strategy for breakfast." Nowhere is that better depicted than in the challenges that persist in enacting the good science that now exists around best practices in blood transfusion.

\section{References}

1. Murphy GJ, Pike K, Rogers CA, Wordsworth S, Stokes EA, Angelini GD, et al. Liberal or restrictive transfusion after cardiac surgery. N Engl J Med. 2015;372: 997-1008.

2. Mazer CD, Whitlock RP, Fergusson DA, Hall J, Belley-Cote E, Connolly K, et al. Restrictive or liberal red-cell transfusion for cardiac surgery. N Engl J Med. 2017; 377:2133-44.

3. Hajjar LA, Vincent J-L, Galas FRBG, Nakamura RE, Silva CMP, Santos MH, et al. Transfusion requirements after cardiac surgery: the TRACS randomized controlled trial. JAMA. 2010;304:1559-67.
4. Bhaskar B, Dulhunty J, Mullany DV, Fraser JF. Impact of blood product transfusion on short and long-term survival after cardiac surgery: more evidence. Ann Thorac Surg. 2012;94:460-7.

5. Chandra S, Kulkarni H, Westphal M. The bloody mess of red blood cell transfusion. Crit Care. 2017;21(Suppl 3):310.

6. Vamvakas EC, Blajchman MA. Blood still kills: six strategies to further reduce allogeneic blood transfusion-related mortality. Transfus Med Rev. 2010;24: 77-124.

7. Fitzgerald DC, Simpson AN, Baker RA, Wu X, Zhang M, Thompson MP, et al. Determinants of hospital variability in perioperative red blood cell transfusions during coronary artery bypass graft surgery. J Thorac Cardiovasc Surg. 2022; 163:1015-24.e1.

8. Fischer F, Lange K, Klose K, Greiner W, Kraemer A. Barriers and strategies in guideline implementation - a scoping review. Healthcare. 2016;4:36.

9. Zenati MA, Kennedy-Metz L, Dias RD. Cognitive engineering to improve patient safety and outcomes in cardiothoracic surgery. Semin Thorac Cardiovasc Surg. 2020;32:1-7.

10. Wahr JA, Prager RL, Abernathy JH, Martinez EA, Salas E, Seifert PC, et al. Patient safety in the cardiac operating room: human factors and teamwork. Circulation. 2013;128:1139-69.

\section{See Article page 1015.}

\section{Commentary: Like politics, transfusion practice is local}

\section{Muhammad Aftab, MD, and T. Brett Reece, MD}

Ever growing numbers of studies have demonstrated an association between red blood cell (RBC) transfusion and adverse surgical outcomes and increasing costs after cardiac surgery. ${ }^{1-3}$ Initiatives to reduce blood transfusions in cardiac surgery patients have included blood conservation practice guidelines from the Society of Thoracic Surgeons, Society of Cardiovascular Anesthesiologists, and European Association for Cardio-Thoracic Surgery/European Association of Cardiothoracic Anaesthesiology. 4,5

Liberal and restrictive transfusion approaches have been studied widely in cardiac surgery. The TRICS trial randomized 5243 moderate- to high-risk adult cardiac surgery patients to liberal and restrictive strategies. The results

From the Division of Cardiothoracic Surgery, Department of Surgery, University of Colorado, Aurora, Colo.

Disclosures: The authors reported no conflicts of interest.

The Journal policy requires editors and reviewers to disclose conflicts of interest and to decline handling or reviewing manuscripts for which they may have a conflict of interest. The editors and reviewers of this article have no conflicts of interest.

Received for publication May 3, 2020; revisions received May 3, 2020; accepted for publication May 4, 2020; available ahead of print May 14, 2020.

Address for reprints: T. Brett Reece, MD, Division of Cardiothoracic Surgery, Department of Surgery, University of Colorado, 12631 E 17th Ave, MS C310, AO1 Rm 6610, Aurora, CO 80045 (E-mail: brett.reece@cuanschutz.edu).

J Thorac Cardiovasc Surg 2022;163:1026-7

0022-5223/\$36.00

Copyright (c) 2020 by The American Association for Thoracic Surgery

https://doi.org/10.1016/j.jtcvs.2020.05.005

\section{Check for updates}

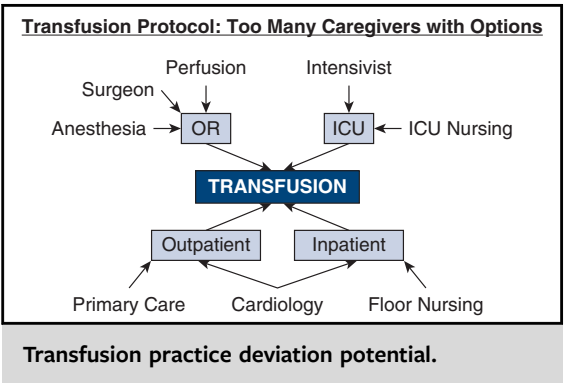

CENTRAL MESSAGE

Wide center-level variability ex-

ists in the RBC transfusion prac-

tices after CABG surgery which is

independent of patient charac-

teristics. Further studies might

explain this variation between

the liberal

approach was

noninferior to the restrictive strategy regarding a composite endpoint of death, myocardial infarction, stroke, renal failure requiring dialysis, and fewer blood transfusions. ${ }^{6}$ The TITRe 2 investigators also evaluated both transfusion strategies. The primary outcomes of a serious infection or an ischemic event between both groups showed no differences. However, more deaths occurred in the restrictive group. The authors concluded that the restrictive transfusion threshold was not superior to the liberal approach concerning 